16,09

\title{
Неупругое рассеяние света самосформированными линейно-цепочными агрегатами углеродных атомов в островковых пленках золота
}

\author{
(C) М.Е. Компан, О.И. Коньков, С.Е. Никитин, А.В. Анкудинов \\ Физико-технический институт им. А.Ф. Иофрфе РАН, \\ Санкт-Петербург, Россия \\ E-mail: kompan@mail.ioffe.ru
}

Поступила в Редакцию 22 декабря 2021 г.

В окончательной редакции 22 декабря 2021 г.

Принята к публикации 27 декабря 2021 г.

При исследовании оптического отклика островковых пленок золота обнаружена интенсивная линия в спектре рассеяния света вблизи $2100 \mathrm{~cm}^{-1}$. Рассмотрены некоторые возможные причины появления указанной линии. Сравнение результатов, полученных для пленок, отличающихся по технологиям нанесения, спектров рассеяния света на других типах образцов, а также сравнение с результатами других авторов позволяют интерпретировать линию как результат неупругого рассеяния света одномерными цепочками углерода.

Ключевые слова: пленки золота, карбины, рамановские спектры.

DOI: 10.21883/FTT.2022.04.52191.260

\section{1. Введение}

Уникальные свойства тонких островковых пленок и наночастиц золота (AuNPs), серебра (AgNPs), меди (CuNPs) в последние 20 лет привлекают пристальное внимание исследователей. Фотолюминеценция этих металлов была обнаружена в 1969 году [1]. Для возбуждения золота и меди использовался лазер с длиной волны $488 \mathrm{~nm}$, и фотолюминесценция наблюдалась вблизи $564 \mathrm{~nm}$ (для золота) и $620 \mathrm{~nm}$ (для меди). Слабая люминесценция с низким квантовым выходом $(\mathrm{QY}) \sim 10^{-10}$ была отнесена к межзонным (d-sp) переходам. Длительное время этому направлению исследований не уделялось внимание. В 1974 г. был обнаружен эффект усиления рамановского рассеяния развитой поверхностью серебряного электрода [2]. Явление получило название surface enhanced Raman scattering (SERS) и нашло широкое применение в химическом анализе, биохимии и биологии [3-9]. Возможности использования кластеров золота как оптических зондов в медицине связано с их инертностью, чем было обусловлено активное изучение их оптических свойств. При изучении SERS на пленках $\mathrm{Ag}$ и $\mathrm{Au}$ было найдено, что кроме спектральных полос, характерных для органических материалов, наблюдалось фоновое излучение, исходящее из пленок этих металлов. Было установлено, что полосы фотолюминесценции пленок и наночастиц золота (AuNPs) могут находится в диапазоне от $400 \mathrm{~nm}$ до ближней IR-области, в зависимости от количества атомов золота в наночастицах и их окружения [5-8]. Причем QY таких нанокластеров был в $\sim 10^{5} \div 10^{6}$ раз больше, чем наблюдалось для образцов в [1].
Наиболее интенсивное излучение демонстрируют кластеры золота с размерами от $20 \mathrm{~nm}$ до $0.3 \mathrm{~nm}$, имеющие в своем составе от $\sim 10^{6}$ до нескольких атомов. Ярко люминесцирующие AuNPs чаще всего получают методами химии растворов. Образующиеся при этом золотые частиц близки к критическим размерам зародышей золота в растворе и термодинамически нестабильны, что приводит к большой вероятности их укрупнения [10]. Для стабилизации размеров AuNPs кластеры окружают оболочками, преимущественно из различных органических молекул-лигандов [9]. Подавляющее большинство исследований проводятся именно с такими модифицированными наночастицами золота. Существование оболочек уширяет спектральные линии и усложняет интерпретацию спектров фотолюминесценции. Нельзя также исключить влияние на спектры излучения остаточных следов реагентов, участвующих в процессе образования золотых нанокластеров. Поэтому, несмотря на большое число исследований, природа свечения собственно AuNPs остается не до конца ясной.

Ранее в работе [11], авторами методом магнетронного распыления были получены островковые пленки золота на медных подложках. Поверхность полученных пленок золота была исследована с помощью сканирующей электронной микроскопии. Пленки представляли собой слой, состоящий из золотых частиц (приблизительно сфероидов) $\sim 30-40 \mathrm{~nm}$. При возбуждении таких золотых пленок Не-Ne лазером $(632.8 \mathrm{~nm})$ авторами была обнаружена интенсивная и узкая полоса излучения вблизи $733 \mathrm{~nm}$. Ширина полосы составляла $\sim 0.016 \mathrm{eV}$, что более чем на порядок меньше, чем типичные ширины полос люминесценции, наблюдаемых в AuNPs в растворах. Указанная полоса в спектре наблюдалась и у образцов, 
хранившихся течение длительного времени (более года). Следует отметить, что полученные наночастицы золота не имели искусственно созданных стабилизирующих оболочек.

Настоящая работа исходно была нацелена на выяснение природы излучения безоболочечных золотых нанокластеров, находящихся на поверхности различных подложек.

\section{2. Техника экспериментов и приготовление образцов}

Образцы для экспериментов - пленки золота различной толщины напыляли катодным или магнетронным напылением на различные подложки. Также в экспериментах использовалось коллоидное золото, высушенное из водных растворов.

В качестве подложек применялись стандартные стекла для микроскопии, пластины кремния, и, в отдельных экспериментах, медная и алюминиевая фольги. Также в некоторых случаях, перед напылением золота на стеклянную подложку наносили медный или алюминиевый подслой. Нанесение металлических слоев меди и алюминия проводилось методом испарения электронным пучком на установке STE EB 48. при температурах $140-1500^{\circ} \mathrm{C}$ в базовом вакууме не хуже $1 \cdot 10^{-6}$ Ра. Толщины слоев $\mathrm{Cu}$ и $\mathrm{Al}$ составляли 100 и $150 \mathrm{~nm}$. Вакуум во время напыления был порядка $10^{-5} \mathrm{~Pa}$, скорость роста $0.5-0.7 \mathrm{~nm} \cdot \mathrm{s}^{-1}$.

Нанесение слоя золота проводилось методами катодного и магнетронного распыления золотой мишени чистотой 99.9 на установках МСМ 100 и ВУП-5 при комнатной температуре. В части образцов намеренно создавался градиент толщины слоя золота. Для этого использовали расположение подложек на разном расстоянии от геометрического центра распыления мишени. При этом достигнуты изменения толщин от практически 0 до сплошной пленки толщиной $40 \mathrm{~nm}$. Средние толщины конкретных образцов в области измерения оптических свойств определялись расчетным образом, исходя из известной скорости напыления.

В части опытов объектом являлись высушенные коллоидные частицы золота. В этом случае образец для опытов приготавливался следующим образом: капля розового водного раствора коллоидного золота высушивались на воздухе на стеклянной или полированной металлической подложке. Капля высыхала, образуя заметный след по внешнему краю капли. Такой профиль следа высохшей капли является результатом капиллярных потоков и механизм такого явления известен [12].

Оптические эксперименты по неупругому рассеянию света выполнялись на модульном микрорамановском спектрометре HORIBA-JY MRS320, с возбуждением светом $\mathrm{He}-\mathrm{Ne}$ лазера с длиной волны $632.81 \mathrm{~nm} \mathrm{c}$ микроскопом OLIMPUS BX41. Основной массив спек- тров получен с объективом MPlan N 50/0,75. Опыты проводились при комнатной температуре.

Для изучения рельефа исследуемых пленок использовался: атомно-силовой микроскоп (AFM) Интегра Аура (НТ-МДТ), режим прерывистого контакта, кантиливер HA_NC_A, осциллирующий на резонансной частоте $224 \mathrm{kHz}$ с амплитудой свободных и рабочих осцилляций 20 и $15 \mathrm{~nm}$.

\section{3. Результаты}

Основным экспериментальным результатом, полученным в настоящей работе, является наблюдение узкой полосы в спектре неупругого рассеяния света на тонких островковых пленках и коллоидах золота. Как упоминалось выше, впервые аналогичную полосу в области около $2100 \mathrm{~cm}^{-1}$ ( 720-730 nm) авторы наблюдали для двухслойных пленок медь-золото [11]. (Далее понятие „Пленка“ будет использоваться как общий термин для напыленного материала, как для сплошных пленок, так и предельно тонких, состоящих из отдельных кластеров.) В данной работе исследования проводились на большом массиве образцов на различных подложках, что дало возможность детального изучения эффекта.

В новой серии экспериментов обсуждаемая полоса наблюдалась на подавляющем большинстве образцов. Прежде всего, эксперименты выявили, что полоса наблюдается в спектрах свечения золотых пленок, нанесенных на различные подложки - стекло, медь, алюминий, кремний. На относительно толстых (сплошных) пленках ее интенсивность существенно слабее - на полтора-два порядка. Положение полосы незначительно варьировалось в зависимости от технологий нанесения и типа подложек. Причины проявления нестабильности будут обсуждены далее. Интенсивность полосы могла зависеть от точки образца, в которой снимался спектр, что, по-видимому, объясняется недостаточной равномерностью напыления. Положениие полосы свечения для золотых пленок, нанесенных на алюминиевые, кремниевые или стеклянные подложки, могло незначительно отличаться (на $10-20 \mathrm{~cm}^{-1}$ ). У образцов с напылением золота на медный подслой полоса свечения лежала заметно дальше от линии возбуждения. Дополнительный сдвиг полосы в спектре таких образцов (относительно положения полос для образцов со стеклянной или алюминиевой подложкой) составлял $20-30 \mathrm{~cm}^{-1}$ (около $\sim 3 \mathrm{meV}$ или $\sim 1 \mathrm{~nm})$. В некоторых экспериментах эта разность положений составляла до $70-80 \mathrm{~cm}^{-1}$ (в сторону более длинных волн), рис. 1 и 2.

Рассмотрим данные оптических экспериментов. Показанная на рис. 1 полоса - спектр свечения тонкой золотой пленки, толщиной $\sim 3-5 \mathrm{~nm}$ на стеклянной подложке. Для пленок большей толщины можно отметить небольшое уширение полосы со стороны бо́льших рамановских сдвигов. 
Положение полос в спектрах золота, на подложках с медным подслоем, характеризовалось бо́льшим спектральным сдвигом относительно линии возбуждения $(632.8 \mathrm{~nm})$. Для таких образцов ширина полосы была заметно больше. Для образцов с медным подслоем полуширина (FWHM) полосы достигала $150-200 \mathrm{~cm}^{-1}$, тогда как для пленок, нанесенных на стекло, наблюдались существенно более узкие полосы, с полушириной $20-30 \mathrm{~cm}^{-1}$. В некоторых случаях основная линия сопровождалась слабым спутником с бо́льшим стоксовым сдвигом. У образцов, напыленных на медный подслой, наблюдался вполне разрешаемый спектральный дублет. Эксперименты проводились также с золотыми коллоидами, полученными из водных растворов. В этих экспериментах результат - существование полосы в спектре -

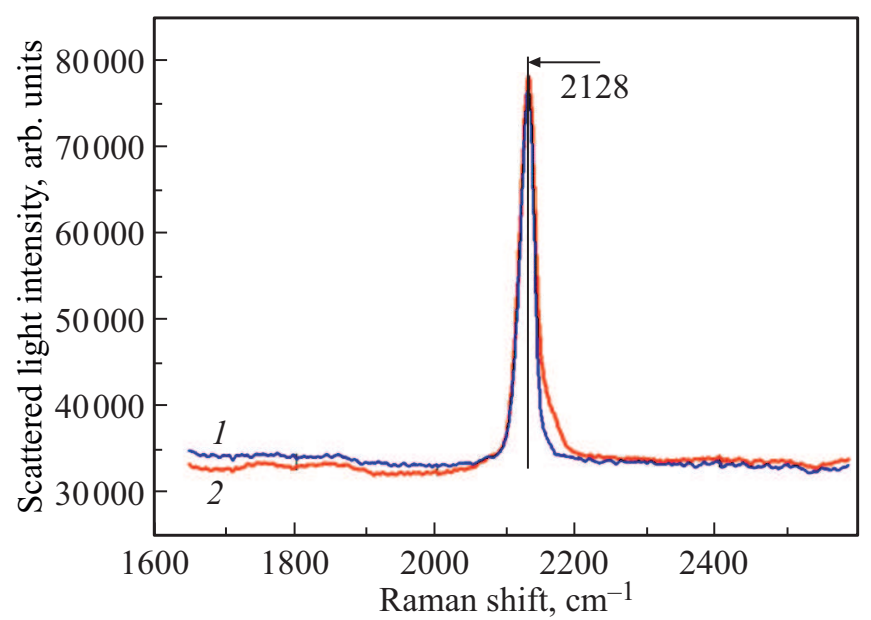

Рис. 1. Спектры рассеяния света островковой пленкой золота на стекле в области $1600-2600 \mathrm{~cm}^{-1} .1-$ спектр рассеяния в области пленки толщиной $\sim 3 \mathrm{~nm} ; 2-$ спектр рассеяния в области пленки толщиной $\sim 5 \mathrm{~nm}$. Спектры нормированы по максимуму.

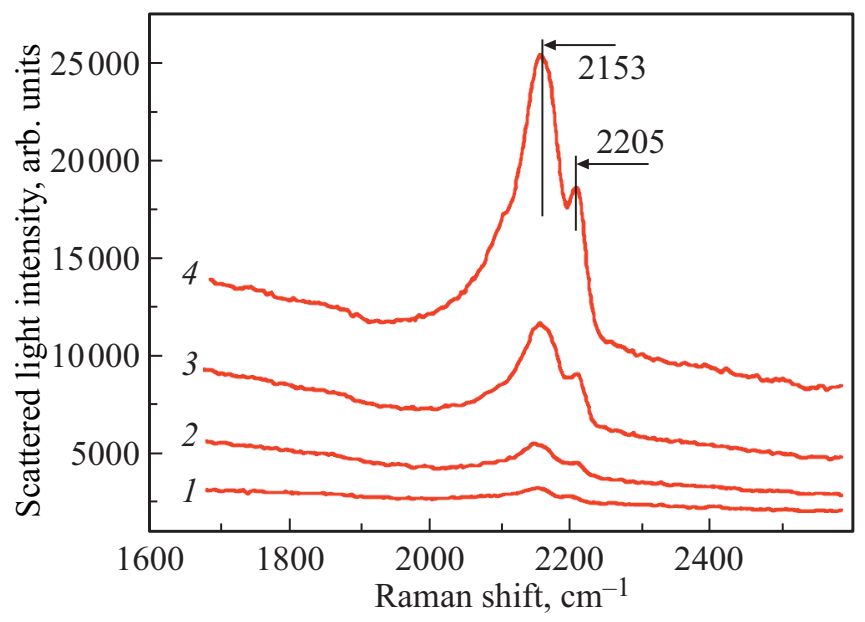

Рис. 2. Спектр рассеяния света островковой пленкой золота на медном подслое. Расчетные толщины золотой пленки для кривых 1,2, 3, $4-35 \mathrm{~nm}, 15 \mathrm{~nm}, 7 \mathrm{~nm}, 3 \mathrm{~nm}$.

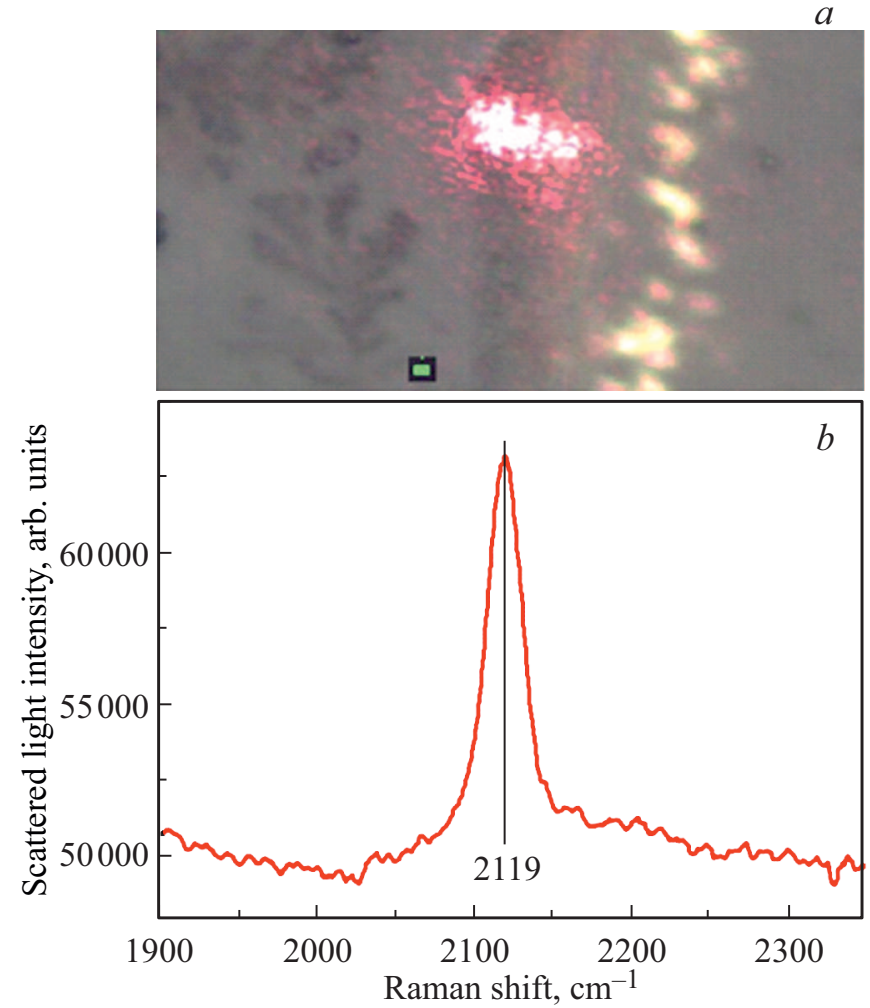

Рис. 3. $a-$ микрофотография края высушенной капли коллоидного раствора золота. На рисунке справа, за светлой полосой - чистая подложка. Горизонтальный размер масштабной метки $1.8 \mu \mathrm{m}$. Край капли содержит несколько слоев осадков; ярко освещенные - крупные золотые частицы. Лазер, возбуждающий свечение, сфокусирован левее, на темную полосу; $b$ - спектр неупругого рассеяния света от следа капли в области $1900-2300 \mathrm{~cm}^{-1}$.

зависел от способа, которым приготавливался раствор золотых коллоидов. Полосу удавалось наблюдать для случая, когда коллоидный раствор получался стандартным цитратным методом [13]. Внешний вид края высохшей капли раствора коллоидов, полученных цитратным методом, и спектр наблюдавшейся в этом случае полосы показаны на рис. 3, $a, b$. На микрофотографии видно, что край следа капли неоднороден: крупные и мелкие частицы при высыхании оседали в различных областях следа края. Однако обсуждаемая полоса не наблюдалась в аналогичном образце, когда применялся коллоидный раствор, полученный с применением неорганических реактивов. Обнаруженная зависимость появления полосы в спектре от способа получения коллоидов будет обсуждена в статье далее.

О структуре напыленных пленок можно судить по профилю поверхности, показанному на рис. 4. На рисунке видно, что полученная в наших условиях пленка состоит из отдельных гранул (кластеров) золота, с размерами от $10-30 \mathrm{~nm}$. Более точное определение размеров кластеров ограничено разрешающей способностью AFM микроскопа. Зафиксированный островковый 
характер пленки существенен для понимания результатов исследования. Также, для более обоснованного последующего анализа полученных данных, нами были

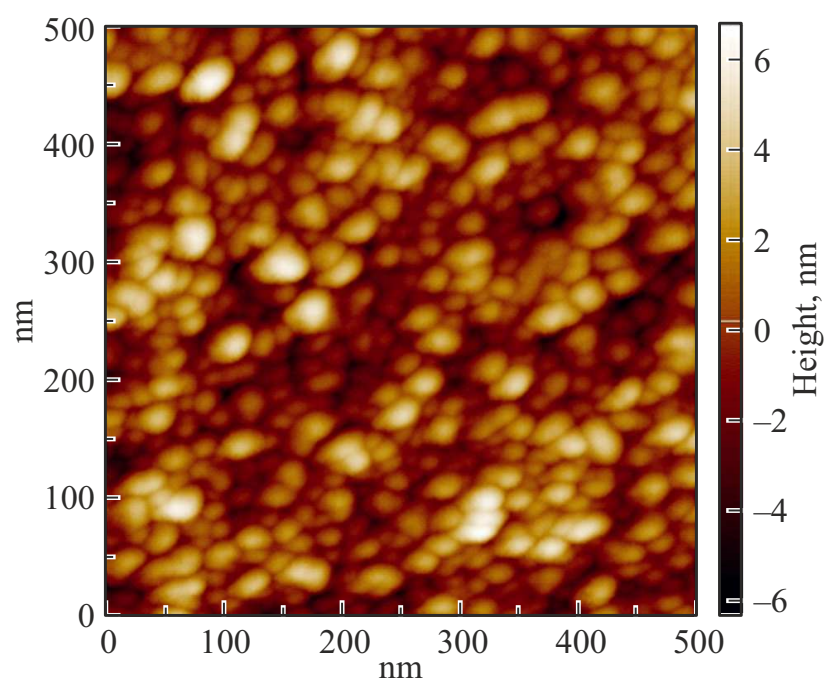

Рис. 4. АFМ-изображение поверхности пленки золота, нанесенной на стеклянную подложку. Масштабы приведены на рисунке.

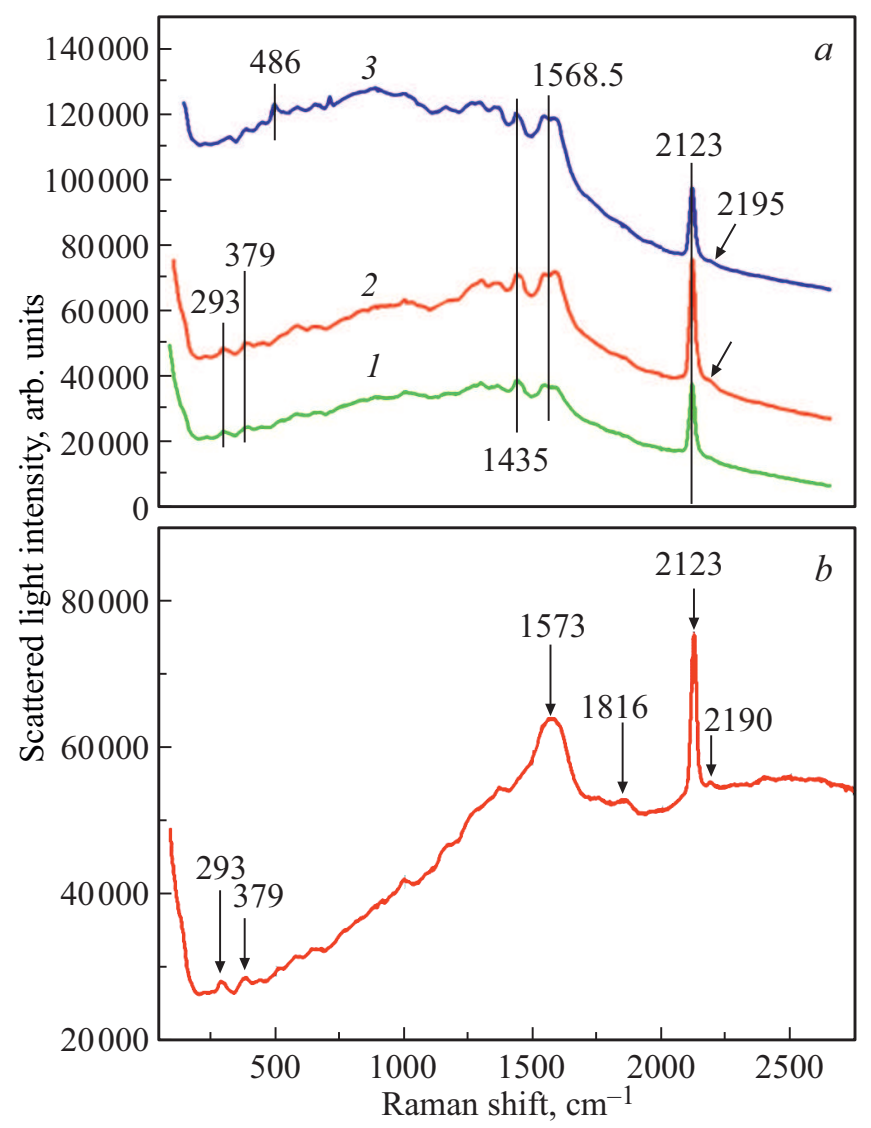

Рис. 5. Спектры неупругого рассеяния от толстой $(40 \mathrm{~nm})(a)$ и $(b)$ тонкой $(3-5 \mathrm{~nm})$ пленок. Слабая линия около $2123 \mathrm{~cm}^{-1}$ обозначена стрелкой. Обсуждение в тексте. Три спектра на рис. 5, $a-$ от разных точек образца. Спектры для лучшего восприятия разнесены по вертикали. зарегистрированы спектры свечения пленок в более широком диапазоне энергий. На рис. 5, $a, b$ приведены такие спектры в диапазоне рамановского сдвига $100-2750 \mathrm{~cm}^{-1}$ от линии возбуждения. На показанных спектрах видно, что, хотя линия $2100 \mathrm{~cm}^{-1}$ и является наиболее заметной деталью спектров в этом диапазоне, существуют и другие линии. Анализ и интерпретация этих данных будут проведены в разделе „обсуждение результатов“.

\section{4. Обсуждение результатов}

При анализе и интерпретации результатов авторы исходят из предположения, что узкие полосы свечения, наблюдавшиеся в области $2100 \mathrm{~cm}^{-1}$ в спектрах рассеяния различных образцов пленок золота, есть один и тот же объект, обусловленный одной и той же причиной во всех случаях.

Необычные свойства наблюдающегося свечения в первую очередь заставляют поставить вопрос, не является ли это наблюдение ошибкой эксперимента.

Обсуждаемая полоса наблюдалась только на образцах с золотой пленкой. Ни на каких других образцах такая полоса не наблюдалась. Контрольные эксперименты с образцами проводились на двух других установках. На одной из них, линия наблюдалась при возбуждении, аналогичном нашему - светом с длиной волны $632.8 \mathrm{~nm}$, и не наблюдалась при длине возбуждения $514 \mathrm{~nm}$ ни в области $2110-2150 \mathrm{~nm}^{-1}$, ни в области около $720-730 \mathrm{~nm}$ (в случае, если бы это была люминесценция). На еще одной установке при возбуждении $532 \mathrm{~nm}$ на образце с медным подслоем наблюдались слабые следы линии $2160 \mathrm{~cm}^{-1}$. Таким образом, зафиксированное свечение не является ошибкой эксперимента.

Для дальнейшего анализа необходимо определиться с природой полосы: является ли наблюдаемое свечение люминесценцией или линия в спектре соответствует неупругому рассеянию света. Имеющиеся данные позволяют однозначно ответить на такой вопрос. Столь узкая ширина наблюдающейся полосы не характерна для люминесценции, и типична для рамановских спектров. Кроме того, эксперимент с возбуждением светом с длиной волны $532 \mathrm{~nm}$ показал слабый максимум в области вблизи $2100 \mathrm{~cm}^{-1}$, и не показал полосы в области $720-750 \mathrm{~cm}$, как это было бы в случае люминесценции. Таким образом, наблюдаемая узкая полоса - проявление неупругого рассеяния света.

Более сложный вопрос - что является источником наблюдаемой полосы? Рамановское рассеяние в металлах, насколько авторам известно, не наблюдалось. Даже если бы по каким-то причинам комбинационное рассеяния в металле было бы нами зафиксировано, частота его лежала бы много ниже по энергии из-за большой массы атомов золота. Поэтому, обсуждаемая линия не может быть связана с рамановским рассеянием непосредственно в золоте. Некое вещество, обеспечивающее полосу в 
спектре рассеянного света, должно образовываться при образовании золотых пленок.

Хотя золото принято считать эталоном химической инертности, оно может окисляться, в том числе в среде электрического разряда в газе - т.е. в условиях, которые использовались для его напыления в нашем случае. Известны два типа оксидов золота $\mathrm{Au}_{2} \mathrm{O}$ и $\mathrm{Au}_{2} \mathrm{O}_{3}[14,15]$. $\mathrm{B}$ работе [16] рассчитаны некоторые параметры этих материалов. По результатам работы [16] оба оксида являются полупроводниками с шириной запрещенной зоны несколько менее $1 \mathrm{eV}$. Это еще одна причина, по которой обсуждаемая полоса не может являться люминесценцией образовавшихся на поверхности золота оксидов.

В работе [16] рассчитаны также колебательные моды вышеприведенных оксидов. Все колебательные моды решеток этих оксидов лежат ниже $500 \mathrm{~cm}^{-1}$. Это подтверждает высказанные выше очевидные соображения, что соединения тяжелых элементов не могут иметь моды решеточных колебаний в области $2100 \mathrm{~cm}^{-1}$. Следовательно, обсуждаемая полоса должна отвечать неупругому рассеянию на веществе, образование которого происходит при получении пленок Аu.

Заметим дополнительно, что в полученных спектрах (рис. $5, a, b$ ) достаточно устойчиво проявляются слабые линии в области $300-500 \mathrm{~cm}^{-1}$, что может быть проявлением рассеяния в оксидах, однако это не является предметом данной работы.

Анализ имеющихся публикаций выявил, что линии, близкие к $2100 \mathrm{~cm}^{-1}$, могут наблюдаться при рассеянии света на молекулах оксида углерода $\mathrm{CO}$, а также при рассеянии на линейных цепях углерода с sp конфигурацией (карбинах). Оба вещества могли образоваться при напылении золотых пленок. Кислород, необходимый для образования СО, мог присутствовать в напылительной камере как остаточный газ. Углерод, необходимый для обоих материалов, мог образовываться при разрушении в электрическом разряде паров вакуумного масла из откачной системы. Близость положений полос в спектрах СО и карбина обусловлена тем, что в обоих случаях линия отвечает колебаниям атомов, связанных тройной химической связью $-\mathrm{C} \equiv \mathrm{C}-$ и $\mathrm{C} \equiv \mathrm{O}$, а массы колеблющихся атомов в этом случае близки. То, что карбиновые цепочки (на подложке) могут образовываться при электрическом разряде в газе, экспериментально подтверждено в работе [17].

Рассмотрим причины, по которым обсуждаемая полоса в спектре не может принадлежать молекулам СО. Прежде всего, содержание СО в атмосферном воздухе мало $\left(0.01-0.05 \cdot 10^{-3} \mathrm{~g} / \mathrm{m}^{3}\right)$ и имеет смысл обсуждать возможность рассеяния молекулами адсорбированным на поверхности. Молекулы СО в принципе могли образовываться в электрическом разряде в присутствии паров вакуумного масла и остаточного кислорода. Однако температура десорбции СО с поверхности золота менее $200 \mathrm{~K}$ [18] (эта величина различается для разных кристаллических плоскостей, здесь указана максимальная цифра). В работе [19] показано, что при комнатной температуре следы СО на поверхности островковой пленки золота исчезают за время около 10 часов. В наших экспериментах обсуждаемая линия детектировалась и в образцах, хранившихся более года. Наконец, в спектрах образцов, полученных в среде аргона (т.е. в отсутствие кислорода) линия детектировалась примерно с той же интенсивностью, как и в предыдущих экспериментах. Все это позволяет исключить рассеяние на молекулах монооксида углерода как возможный вариант интерпретации.

Еще один экспериментальный факт дополнительно исключает возможность интерпретации обсуждаемой линии как проявление рассеяния на молекулах $\mathrm{CO}$, и одновременно, свидетельствует в пользу гипотезы о рассеянии в линейных агломератах углерода. Упомянутая выше вариабельность положения этой линии в спектре не может соответствовать рассеянию на молекуле СО. Это относительно простая молекула, имеющая одну моду колебаний $[20,21]$, частота которой не должна зависеть от внешних факторов. Тем более не просматривается причина возможности появления расщепления и появления дублета в спектре (рис. 2). По нашему мнению, это однозначный аргумент для подтверждения нашей интерпретации экспериметов.

В то же время известно, что частота колебания фрагмента $-\mathrm{C} \equiv \mathrm{C}-$, которая находится вблизи положения $\sim 2100 \mathrm{~cm}^{-1}$, должна зависеть от ряда причин: от длины цепи, а также от того, каким способом замыкается линейная цепочка [22]. По-видимому, на частоту может влиять и возможное ветвление от нерегулярного атома углерода в цепочке. Таким образом, помимо исключения альтернативных интерпретаций, зафиксированная вариативность положения линии однозначно указывает на линейную цепь атомов углерода, как на источник линии $2100 \mathrm{~cm}^{-1}$ в спектре рассеяния.

Пока нельзя однозначно указать на вторую линию, которая должна проявляться в спектрах карбинов. Линия $\sim 2100 \mathrm{~cm}^{-1}$ соответствует колебанию тройной вязи в углеродной цепи $-\mathrm{C} \equiv \mathrm{C}-\mathrm{C} \equiv \mathrm{C}-\mathrm{C}-$. Но в такой цепи должна присутствовать и линия, соответствующая одинарной связи. Положение этой линии по разным публикациям, может находиться в области $\left(1100-1600 \mathrm{~cm}^{-1}\right)$, что приходится на диапазон полосы аморфного углерода. Кроме того, линия, отвечающая колебаниям одинарной связи, должна быть существенно слабее линии тройной связи [22-24]. В полученных нами спектрах (рис. 5, $a, b)$, в указанной области проявляются полосы, близкие по положению к полосе $\mathbf{s p}^{2}$ графита (но явно более широкие, чем полосы кристаллического графита). Также в указанной спектральной области просматриваются и несколько других полос, которые мы не можем интерпретировать однозначно, но которые могут отвечать одиночной связи $\mathrm{C}-\mathrm{C}$ в углеродной цепочке.

Эксперименты с высушенными коллоидами, несмотря на то, что это объект иной природы, также косвенно подтверждают предложенную нами интерпретацию. Линия 
$2100 \mathrm{~cm}^{-1}$, обсуждаемая нами, должна соответствовать колебаниям фрагмента $-\mathrm{C} \equiv \mathrm{C}-$. Продукты реакции при получении золота цитратным способом содержат такие фрагменты, а при получении с применением неорганических реактивов такие фрагменты отсутствуют [13]. Это еще одно экспериментальное подтверждение нашей интерпретации.

Не вполне ясно, почему напыление на медь приводит к заметному отличию положения полосы; чем это отличается от других случаев. Остается предполагать, что медь, как достаточно активный материал, каким-то образом влияет на характер процесса самоформирования углеродных структур.

Наконец, до сих пор в обсуждении не рассматривалось роль золота. По нашему мнению, роль золота двоякая. Важная роль золота - обеспечение возможности наблюдать рассеяние от предельно малых количеств линейных (карбиновых) цепей углерода. Как упоминалось, золото - эффективный материал усиления сигнала рассеяния света поверхностью (SERS) [2]. В нашем случае важность этого механизма подтверждается наблюдавшейся обратной зависимостью интенсивности сигнала рассеяния от толщины пленки - сигнал был минимальный на наиболее толстой части пленки, где золото было напылено сплошным слоем.

Кроме того, учет роли золота за счет усиления эффектом SERS согласуется с обнаруженной зависимостью сигнала от длины волны возбуждающего света. В работе [25] анализируется соотношение действительной и мнимой компонент диэлектрической восприимчивости золота на оптических частотах. Авторы приходят к выводу, что в диапазоне около $600 \mathrm{~nm}$ усиление должно быть наиболее эффективным. Это согласуется с результатами наших экспериментов при возбуждении свечения светом с различными длинами волн.

Помимо оптического усиления, золото, по-видимому, играет и структурную роль. В работе [23] указывается, что кластеры золота могут служить эффективными терминальными звеньями при самоформировании карбиновых цепей и тем самым стабилизируют их. Более детально этот вопрос рассмотрен в [26] где приведены модели стабилизации карбиновых цепей на поверхности переходных металлов, в частности золота. Это еще один возможный фактор влияния типа металла подложки на результат наших опытов.

\section{5. Заключение}

Таким образом: в настоящей работе при исследовании неупругого рассеяния света в островковых пленках золота была обнаружена узкая полосы в спектрах вблизи $2100 \mathrm{~cm}^{-1}$. Анализ данных, полученных на широкой гамме образцов, и сравнение с литературными данными позволили индентифицировать наблюдавшуюся линию, как линию рамановского рассеяния, соответствующую колебанию атомов углерода в линейных цепочках $-\mathrm{C} \equiv \mathrm{C}-$.

\section{Благодарности}

Авторы пользуются случаем поблагодарить В.Ф. Сапегу за проведение контрольных опытов с использованием других длин волн возбуждающего света.

\section{Конфликт интересов}

Авторы заявляют, что у них нет конфликта интересов.

\section{Список литературы}

[1] A. Mooradian. Phys. Rev. Lett. 22, 185 (1969).

[2] M. Fleischmann, P.J. Hendra, A.J. Mc Quillan. Chem. Phys. Lett. 26, 2, 163 (1974).

[3] B. Sharma, R.R. Frontiera, A.I. Henry, E. Ringe, R.P. Van Duyne. Mater. Today 15, 1-2, 16 (2012).

[4] R.M. Jarvis, N. Law, I.T. Shadi, P. O’Brien, J.R. Lloyd, R. Goodacre. Anal. Chem. 80, 6741 (2008).

[5] G.T. Boyd, Z.H. Yu, Y.R. Shen. Phys. Rev. B 33, 7923 (1986).

[6] J.P. Wilcoxon, J.E. Martin, F. Parsapour, B. Wiedenman, D.F. Kelley. J. Chem. Phys. 108, 9137 (1998).

[7] M.B. Mohamed, V. Volkov, S. Link, M.A. El-Sayed. Chem. Phys. Lett. 317, 517 (2000).

[8] J. Zheng, C. Zhou, M. Yu, J. Liu. Nanoscale 4, 4073, (2012).

[9] E. Porret, X. Le Guer'vel, J.-L. Coll. J. Mater. Chem. B 8, 2216 (2020).

[10] A. Henglein. J. Phys. Chem. 97, 5457 (1993).

[11] М.Е. Компан, С.Е. Никитин, Б.А.-Т. Мелех, А.В. Нащекин. ФTT 59, 12, 2409 (2017.

[12] R.D. Deegan, O. Bakajin, T.F. Dupont, G. Huber, S.R. Nagel, T.A. Witten. Nature 389, 827 (1997).

[13] Л.А. Дыкман, В.А. Богатырев. Успехи химии 76, 199 (2007).

[14] https:// ru.wikipedia.org/wiki/Оксид золота (III). https:// ru.wikipedia.org/wiki/Оксид золота (I).

[15] B. Koslowski, H.-G. Boyen, C. Wilderotter, G. Kastle, P. Ziemann, R. Wehreberg, P. Oelhafen. Surf. Sci. 475, 1 (2001).

[16] H. Shi, R. Asahi, C. Stampfl. Phys. Rev. B 75, 205125 (2007).

[17] https://hal.archives-ouvertes.fr/hal-03357911.

[18] R. Meyer, C. Lemire, Sh.K. Shaikhutdinov, H.-J. Frund. Gold Bull. 37, 1-2, 72 (2004).

[19] Т.Н. Ростовщикова, М.И. Шилина, Е.В. Голубина, Е.С. Локтева, И.Н. Кротова, С.А. Николаев, К.И. Маслаков, Д.А. Явсин. Изв. АН. Сер. хим. 4, 812 (2015).

[20] К. Кольрауш. Спектры комбинационного рассеяния. Изд-во ИЛ, М. (1952).

[21] P. Dumas, R.G. Tobin, P.L. Richards. Surf. Sci. 171579 (1986).

[22] B. Pan, J. Xiao, J. Li, C. Wang, G. Yang. Sci. Adv. 1, 9, 1:e 1500857 (2015).

[23] L. Ravagnan, F. Siviero, C. Lenardi, P. Piseri, E. Barborini, P. Milani, C. Casari, A.L. Bassi, C.E. Bottani. Phys. Rev. Lett. 89, 28, 28550 (2002).

[24] A. Milani, M. Tommasini, V. Russio, A. Li Bassi, A. Lucotti, F. Cataldo, C.S. Casari. Beilstein J. Nanotechnol. 6, 480 (2015).

[25] M. Futamata. Appl. Opt. 36, 1, 364 (2007).

[26] Q. Yuan, F. Ding. Nanoscale 6, 12727 (2014).

Редактор Ю.Э. Китаев 